\title{
IMPLICAÇÕES DO NOVO CÓDIGO FLORESTAL NO PLANEJAMENTO DO USO DO SOLO DA FAZENDA DE ENSINO, PESQUISA E EXTENSÃO
}

\author{
Rafael Castro Crivelenti, Célia Regina Paes Bueno², Ana Paula Mijone², Gabriel Ferreira Damasceno ${ }^{4}$ \\ ${ }^{1}$ Biólogo, Doutorando em Agronomia, UNESP, Jaboticabal, SP, Brasil - rccrivelenti@yahoo.com.br \\ ${ }^{2}$ Geóloga, Dra ., Depto. de Solos e Adubos, FCAV/UNESP, Jaboticabal, SP, Brasil - crbueno@fcav.unesp.br \\ ${ }^{3}$ Eng ${ }^{\mathrm{a}}$. Agrônoma, Jaboticabal, SP, Brasil - ana_agro_07@yahoo.com.br \\ ${ }^{4}$ Geógrafo, Mestrando em Agronomia, UNESP, Jaboticabal, SP, Brasil - gabrielfdamasceno@gmail.com
}

Recebido para publicação: 13/04/2013 - Aceito para publicação: 06/01/2014

\begin{abstract}
Resumo
A ocupação do território nacional, por meio da exploração de recursos naturais, ocorre de maneira predatória. O desmatamento e abertura de novas fronteiras agrossilvipastoris têm sido práticas comuns. Porém essas atitudes implicam resultados adversos para o meio ambiente, como degradação dos solos e matas ciliares, assoreamento dos córregos e perda de biodiversidade. Considerando a importância da conservação das florestas, foi instituída a Lei 4.771/1965 (Código Florestal revogado). Entretanto, seus objetivos não obtiveram sucesso devido ao passivo ambiental observado atualmente nas propriedades rurais. Dessa forma, uma nova lei florestal (Lei ${ }^{\circ}$ 12.651/2012) foi aprovada. Diante desse cenário de mudanças, o objetivo do presente artigo foi verificar as implicações da adequação ambiental na Faculdade de Ensino, Pesquisa e Extensão (FEPE) em relação às duas legislações existentes. $\mathrm{O}$ levantamento das informações ambientais foi realizado com o histórico de uso do solo por meio de fotografias áreas. A partir desses dados, foram elaborados os mapas da propriedade, com o auxílio de sistemas de informações geográficas (SIG). Foi observado que, segundo a legislação aprovada em 2012, houve uma redução da área protegida de reserva legal (50\%). Por outro lado, houve um aumento de $323 \%$ de vegetação nativa nas áreas protegidas e de uso pleno nos últimos 40 anos.

Palavras-chave: Zoneamento ambiental; sistemas de informações geográficas; áreas de preservação.
\end{abstract}

\begin{abstract}
Implications of the new forest code on land use planning of a farm of education, research and extension. The occupation of the country, through the exploration of natural resources occurs in a predatory way. Deforestation and opening of new frontiers has been a common practice. The deforestation has been a common practice. However, these results imply adverse attitudes to the environment such as degradation of soils and riparian forest, siltation of streams and biodiversity loss. Considering the importance of forest conservation, Law 4.771/1965 was instituted. However, its goals were not successful because of environmental liabilities currently observed in the farms. Thus, a new law (Law no. 12.651/2012) was approved. According to this scenario, the objective of this article was to investigate the implications of environmental compliance at the Faculty of Education and Research (FEPE) compared to the two existing laws. The survey of environmental information was based on historical use of land areas through photographs. Based on these data were drawn maps of the property with the help of Geographic Information Systems (GIS). It was observed that, according to the law proposed in 2012, there was a reduction in the protected area of legal reserve (50\%). On the other hand, there was an increase of 323\% of native vegetation in protected areas and of full use of the last 40 years.

Keywords: Environmental zoning; geographic information systems; areas of preservation.
\end{abstract}

\section{INTRODUÇÃO}

No Brasil, o processo de colonização e consolidação do território caracterizou-se, principalmente, pela exploração predatória dos recursos naturais. O desmatamento de encostas e matas ciliares e o uso inadequado do solo são práticas frequentes que afetam de maneira negativa a qualidade e disponibilidade dos recursos hídricos. Ao longo dos séculos, extensões de matas foram degradadas em função das atividades de agropecuária (RIBEIRO et al., 2005). 
As matas ciliares exercem funções hidrológicas e ecológicas imprescindíveis para manter a integridade biótica e abiótica do ecossistema (RODRIGUES et al., 2011). Dentre as funções hidrológicas, destacam-se contenção de ribanceiras, diminuição e filtração do escoamento superficial e impedimento do carreamento de sedimentos (LIMA; ZAKIA, 2000). Já as funções ecológicas dessas matas são a formação de microclimas, hábitat, áreas de abrigo e reprodução, corredores de migração da fauna terrestre e entrada de suprimento orgânico (BARRELA, 2000).

Contudo, a intervenção humana tem provocado um efeito desestabilizador sobre esses ecossistemas naturais, interferindo no seu equilíbrio dinâmico. A fragmentação de remanescentes com vistas ao desenvolvimento agrícola, urbano e industrial é um exemplo da ação antrópica nos últimos tempos (TABANEZ; VIANA, 2000). Essa interferência resulta em impactos negativos para o patrimônio genético florestal, como a exaustão do solo, o assoreamento de cursos de água e de nascentes e a destruição da biodiversidade (COGO et al., 2003). Dessa forma, o isolamento da fauna e flora, dentro do contexto de paisagem, pode ocasionar a extinção de diversas espécies (METZGER, 2000).

Assim como na maioria dos países, a degradação das áreas ciliares brasileiras sempre foi fruto do avanço desordenado das fronteiras agrícolas. Esses avanços se caracterizam pela ineficiência e/ou inexistência de planejamento ambiental e não priorizam a delimitação de áreas destinadas para agricultura e áreas destinadas para preservação ambiental (RODRIGUES et al., 2011).

Diante desse contexto, foi instituído o Código Florestal, por meio da Lei 4.771/1965, que sofreu diversas alterações ao longo dos anos, com o objetivo de propiciar a conservação da vegetação e minimizar os impactos negativos da fragmentação florestal. Porém a falta de aplicação desse código frente à realidade do campo em todo o país fez com que uma nova legislação fosse proposta e aprovada (Lei 12.651/2012) (MILARÉ; MACHADO, 2012).

Dadas as modificações na legislação, o objetivo do presente artigo foi verificar as implicações do novo código florestal frente à antiga legislação quanto às novas possibilidades e restrições do uso do solo rural na Faculdade de Ensino, Pesquisa e Extensão (FEPE).

\section{MATERIAL E MÉTODOS}

A área de estudo foi a Fazenda de Ensino, Pesquisa e Extensão (FEPE / FCAV / UNESP), situada no município de Jaboticabal (SP), entre as coordenadas geográficas longitude 48² $16^{\prime} 52^{\prime \prime}$ e

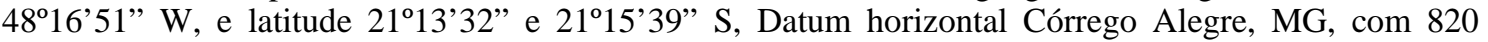
hectares. O relevo local é predominantemente suave ondulado, com cotas variando entre 540 e $640 \mathrm{~m}$, clima mesotérmico de inverno seco (temperatura média anual: $18-22{ }^{\circ} \mathrm{C}$ ) e precipitação média anual de $1.400 \mathrm{~mm}$. O embasamento geológico é constituído por arenitos da formação Adamantina e basaltos da formação Serra Geral. Na área ocorrem cinco classes de solos, classificadas como Latossolos, Nitossolos, Neossolos e Cambissolos.

O levantamento das informações da área de estudo foi realizado por meio de fotografias aéreas e imagens de satélite. As fotografias áreas, na escala de 1:25.000, foram referentes ao ano de 1972, sendo fornecidas pelo Laboratório de Fotointerpretação da Faculdade de Ciências Agrárias e Veterinárias de Jaboticabal. As imagens de satélite foram adquiridas pelo programa Google Earth, referentes ao satélite GeoEye do ano de 2010. A fim de obter um histórico do uso e ocupação da propriedade, as ilustrações foram escaneadas em 300 dpi e posteriormente importadas para o programa ARCGIS.

O georreferenciamento das imagens (sistema de referência UTM 22 Córrego Alegre Sul) foi realizado por meio da aquisição de pontos de controle, com o auxílio das fotografias e do GPS Trackmaker.

O mapa-base foi elaborado por meio da fotointerpretação da imagem GeoEye (referente a outubro de 2010) e pela vetorização da rede de drenagem, curvas de nível, pontos cotados e malha viária. Essas informações estavam contidas na Carta do Brasil, Instituto Brasileiro de Geografia e Estatística (IBGE), escala de 1:50.000, de Taiúva e Jaboticabal.

Posteriormente, foi realizada a checagem de campo, que consistiu nas seguintes etapas: visitas de campo às áreas abrangidas no trabalho de adequação, confirmação das situações identificadas em computador e atualização em relação ao seu uso atual (2012), com correção das eventuais falhas ocorridas durante a análise das imagens.

Com as informações obtidas em campo e o histórico do uso e ocupação da área, foi possível elaborar o mapa de adequação ambiental e avaliar a situação florestal e as restrições de uso da ocupação do solo da propriedade de estudo, de acordo com o Código Florestal de 1965 (MACHADO, 1999), assim como as mudanças ocorridas a partir da nova legislação aprovada (MILARÉ; MACHADO, 2012). 


\section{RESULTADOS E DISCUSSÃO}

Segundo o art.16, item III, da Lei 4.771/1965 (MACHADO, 1999), observou-se que a FEPE apresentava um déficit de 87 hectares para destinação de reserva legal ${ }^{1}$. Em contrapartida, a propriedade encontra-se regularizada de acordo com a legislação atual (Art. 68 da Lei $n^{\circ}$ 12.651/2012), conforme apresentado na figura 1. A figura 2 mostra a baixa expressão de vegetação natĩva já no ano de 1972 , quando não existia o conceito de reserva legal (20\% da área da propriedade), e sim de uma reserva florestal $^{2}$ (20\% da área de vegetação nativa existente na propriedade).
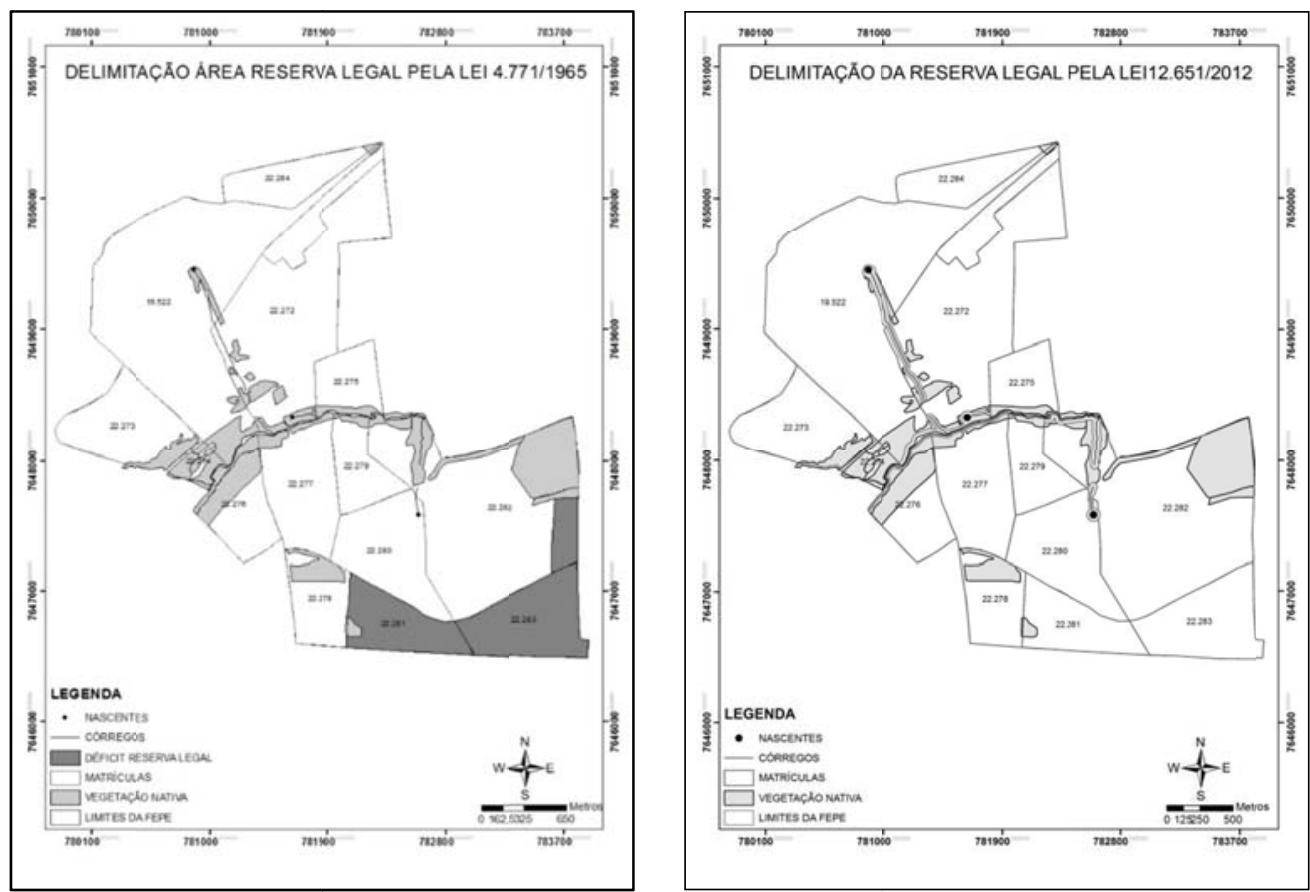

Figura 1. Delimitação das áreas de reserva legal da FEPE pela legislação florestal de 1965 e 2012.

Figure 1. Delimitation of legal reserve areas of forest legislation FEPE 1965 and 2012.

Em relação às Áreas de Preservação Permanente (APP), pode-se dizer que, devido à nova legislação vincular a metragem das APP ao tamanho do imóvel rural, expresso em módulos fiscais ${ }^{3}$, observou-se uma diminuição de $31 \%$ da área considerada como preservação permanente, aplicando-se o dispositivo do Art. 4 e Art. 61-A da Lei 12.651/2012 (Figura 3). Portanto, atividadles consolidadas ${ }^{4}$, como a presença de benfeitorias antes irregulares, passaram a estar de acordo com a nova legislação, uma vez que foram construídas anteriormente ao ano de 2008. Além disto, houve diminuição da área degradada, com destaque para a presença de vegetação nativa em praticamente toda a APP não ocupada por atividades consolidadas, motivo pelo qual se considera que tal área deve ser utilizada no cômputo das áreas de reserva legal, uma vez que a FEPE apresenta poucos remanescentes de vegetação nativa.

\footnotetext{
${ }^{1}$ Área localizada no interior de uma propriedade ou posse rural, delimitada nos termos do art. 12 da Lei Federal 12.651/12, com a função de assegurar o uso econômico de modo sustentável dos recursos naturais do imóvel rural, auxiliar a conservação e a reabilitação dos processos ecológicos e promover a conservação da biodiversidade, bem como o abrigo e a proteção de fauna silvestre e da flora nativa;

${ }^{2}$ Conceito que surgiu em 1934, atualizado na Lei Federal 4.771/1965, ao qual dividia as áreas a serem protegidas de acordo com as regiões, sendo que fixava um mínimo de $20 \%$ das áreas de vegetação nativa a serem mantidas nas florestas de domínio privado;

${ }^{3}$ Unidade de medida fixada diferentemente para cada município de acordo com a Lei $\mathrm{n}^{\circ} 6.746 / 79$, que leva em conta o tipo de exploração predominante no município; a renda obtida com a exploração predominante, outras explorações existentes no município que, embora não predominantes, sejam expressivas em função da renda ou da área utilizada. Em Jaboticabal o módulo fiscal corresponde a 14 hectares;

${ }^{4}$ Área de imóvel rural com ocupação antrópica preexistente a 22 de julho de 2008, com edificações, benfeitorias ou atividades agrossilvipastoris, admitida, neste último caso, a adoção do regime de pousio.
} 


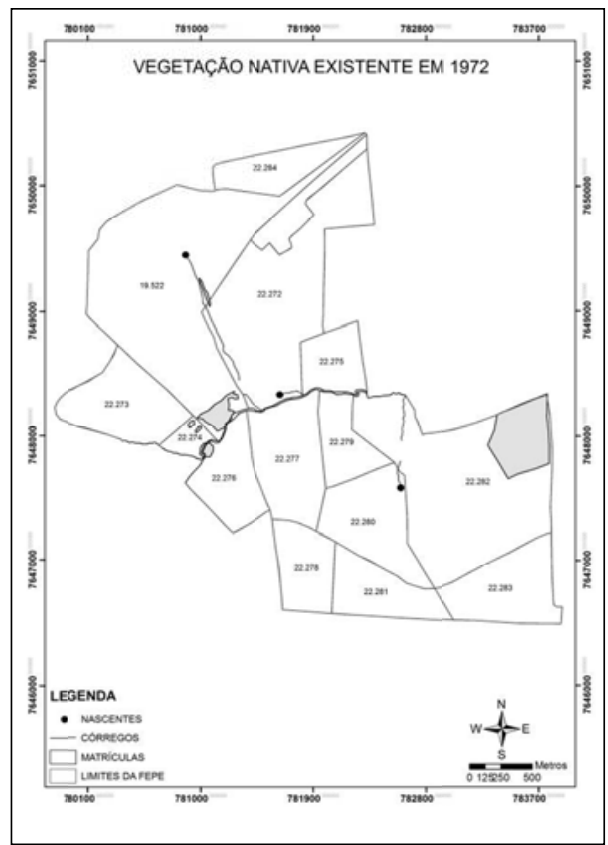

Figura 2. Delimitação das áreas de vegetação nativa da FEPE em 1972.

Figure 2. Delineation of areas of native vegetation FEPE in 1972.

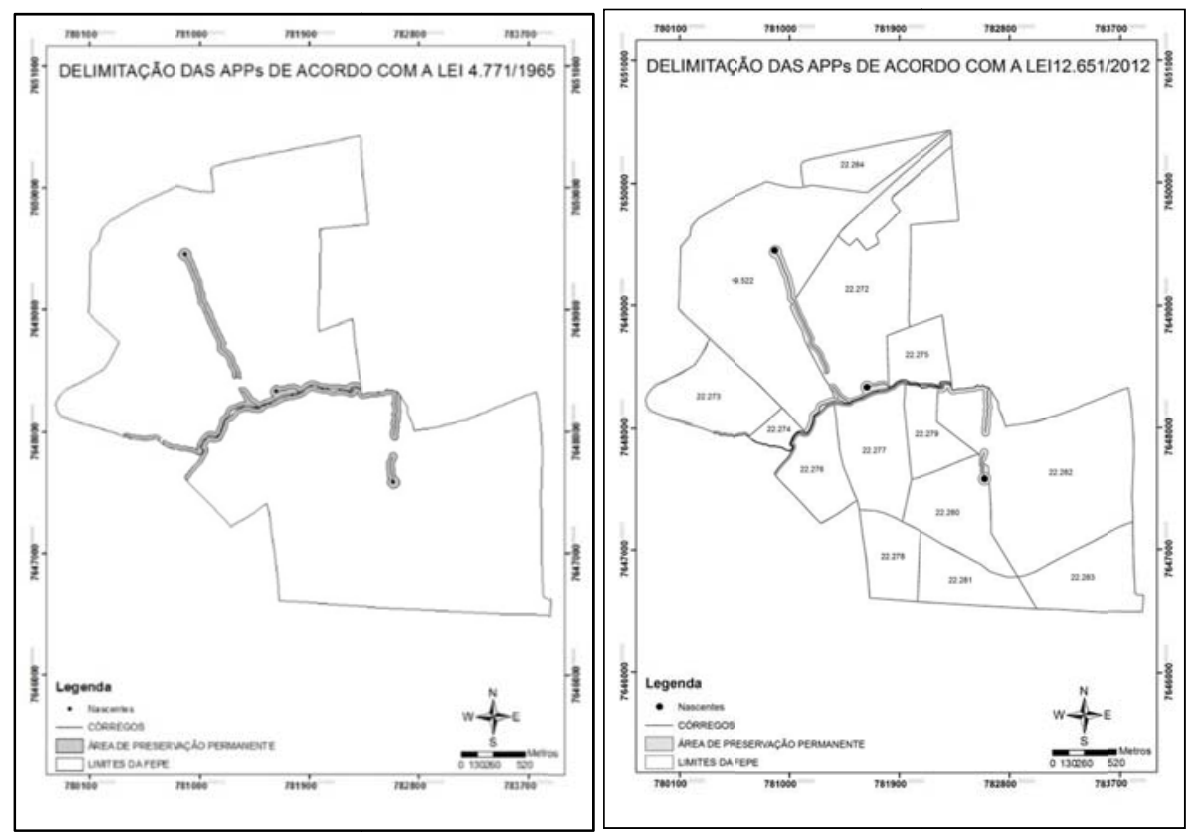

Figura 3. Delimitação das áreas de preservação permanente da FEPE pela legislação florestall de 1965 e 2012. Figure 3. Delineation of areas of permanent preservation of forest legislation FEPE 1965 and 2012.

A tabela 1 apresenta o memorial descritivo das áreas de preservação permanente e reserva legal, em hectares, identificando que aproximadamente 20\% das APP encontravam-se irregularmente ocupadas.

A Lei $\mathrm{n}^{0}$ 4.771/65, através do seu art. 4, itens I e IV (Código Florestal Brasileiro revogado), exigia que os proprietários mantivessem Áreas de Preservação Permanente (APP) nas margens dos rios e nascentes (MACHADO, 1999). No caso da FEPE, a APP ao longo do Córrego Jaboticabal e seus afluentes deveria ser de 30 metros, medidos em projeção horizontal a partir do leito maior sazonal (art. 4, 
item I, alínea “a”), enquanto que ao redor das nascentes o raio protegido deveria ser de 50 metros (art. 4, item IV). Por outro lado, por se tratar de reserva legal, os proprietários deveriam manter $20 \%$ da área total do imóvel para tal destinação.

A partir da aplicação dessa legislação, pode-se observar que a propriedade deveria apresentar seus 27,2 hectares de APP isolados dos fatores de degradação. Porém, a partir da análise do mapeamento realizado e da elaboração do memorial descritivo, nota-se que aproximadamente $20 \%$ das APP encontravam-se irregularmente ocupadas por pastagens, benfeitorias e outras culturas agrícolas, com pouca expressão de vegetação nativa e espécies regenerantes nesses locais, o que possibilita caracterizá-las como área rural consolidada (Tabela 1). Ressalte-se aqui a importância dos projetos de reflorestamento realizados a partir da década de 90, na qual houve o plantio de mais de 20.000 mudas ao longo dos córregos da FEPE e suas margens, uma vez que, se observarmos os dados de 1972, praticamente 95\% das APP encontravam-se degradadas e sem a presença de vegetação nativa (VALERI, 2004).

Tabela 1. Memorial descritivo das áreas de preservação permanente e reserva legal.

Table 1. Descriptive history of permanente preservation areas and legal reserves.

\begin{tabular}{|c|c|c|c|c|c|c|c|c|c|c|c|c|c|c|c|c|}
\hline \multirow{2}{*}{ Matrículas } & \multirow{2}{*}{1965} & \multicolumn{14}{|c|}{2012} & \multirow[b]{2}{*}{ Total } \\
\hline & & 1 & 2 & 3 & 4 & 5 & 6 & 7 & 8 & 9 & 10 & 11 & 12 & 13 & 14 & \\
\hline \multicolumn{17}{|c|}{ APP } \\
\hline Metragem & 30 & 30 & 20 & 15 & 5 & 8 & 15 & 15 & - & 8 & 15 & - & 30 & - & - & - \\
\hline Área total & 27 & 4,3 & 5.6 & 0,5 & 0,3 & 0,5 & 1,3 & 1 & - & 0,2 & 1 & - & 4,3 & - & - & 19 \\
\hline Vegetação & 22 & 2,9 & 3 & 0,4 & 0,3 & 0,5 & 1,2 & 1 & - & 0,2 & 0,5 & - & 4 & - & - & 14 \\
\hline $\begin{array}{l}\text { APP } \\
\text { degradada }\end{array}$ & 1,1 & 0 & 0,4 & 0 & 0 & 0 & 0 & 0 & - & 0 & 0,4 & - & 0,1 & - & - & 0,9 \\
\hline Barramentos & 2,2 & 1,1 & 0,9 & 0 & 0 & 0 & 0 & 0 & - & 0 & 0 & - & 0 & - & - & 2 \\
\hline Benfeitorias & 1,9 & 0,3 & 1,2 & 0 & 0 & 0 & 0 & 0 & - & 0 & 0 & - & 0 & - & - & 1,5 \\
\hline \multicolumn{17}{|c|}{ Reserva legal } \\
\hline Área total & 820 & 176 & 117 & 47 & 8 & 24 & 34 & 51 & 29 & 25 & 48 & 33 & 154 & 46 & 28 & 820 \\
\hline Reserva legal & 164 & 35 & 23 & - & - & - & - & - & - & - & - & - & 32 & - & - & 90 \\
\hline Fragmentos & 76 & 7,5 & 6,6 & 8 & 4,7 & 1,7 & 15 & 2,7 & 3,7 & 1,1 & 0,1 & 0 & 33 & 0 & 0 & 84 \\
\hline Déficit RL & 87 & 25 & 13 & - & - & - & - & - & - & - & - & - & - & - & - & 38 \\
\hline Vegetação & 97 & 10 & 9,7 & 8,4 & 5 & 2,3 & 16 & 3,7 & 3,8 & 1,4 & 0,7 & 0 & 36 & 0 & 0 & 97 \\
\hline
\end{tabular}

Diante da realidade do país frente às irregularidades em relação à legislação florestal na área rural, novas mudanças foram propostas e aprovadas com o Novo Código Florestal Brasileiro (Lei 12.651/2012). Foram elaboradas novas regras para as Áreas de Preservação Permanente e Reserva Legal, com alterações propostas pela Lei 12.727/2012 e pelo Decreto 7.830/2012 (MILARÉ; MACHADO, 2012), o que motivou aplicar a nova legislação à FEPE, que atualmente apresenta área equivalente a 59 módulos fiscais.

Com relação às áreas de Reserva Legal, 164 hectares deveriam ser destinados para tal fim, conforme art. 16, item III, do código revogado. Porém sabe-se que a FEPE encontra-se em um ambiente agrícola com a presença de apenas alguns fragmentos de vegetação nativa isolados na paisagem. Contudo, nada foi realizado em relação à averbação da Reserva Legal, já que a propriedade apresentava aproximadamente 77 hectares de fragmentos florestais, o que implicava um déficit de 87 hectares destinados para fins agrícolas (Figura 1). É importante ressaltar que muitos desses fragmentos estão sob o efeito antrópico do entorno, como presença de lianas superabundantes, presença de gramíneas invasoras, espécies exóticas, risco de incêndios e outros efeitos de borda, como elucidados anteriormente (PINTO, 1989).

Dessa forma, nota-se que o Campus não estava de acordo com a legislação vigente até outubro do ano de 2012. Teoricamente, a propriedade de estudo deveria apresentar 191,2 hectares de área protegida pela Lei 4.771/1965, porém 48\% dessa área estavam ocupados irregularmente.

A legislação atual permite que as propriedades rurais sejam consideradas por meio de suas matrículas. Além disso, a exigência ou não da Reserva Legal e de metragem que define as APP estão vinculadas ao tamanho do módulo fiscal dessas matrículas, que variam de acordo com cada município do país, sendo que o valor do módulo do município de Jaboticabal é de 14 hectares.

Contudo, de acordo com o art.67, parágrafo único, as propriedades de até quatro módulos ficam isentas de apresentarem a recomposição da Reserva Legal quando apresentarem déficit de vegetação nativa. Já o Art. 61-A determina, para as APP consolidadas, a seguinte metragem para recomposição da 
vegetação: até um módulo, recomposição de 5 metros; de um a dois módulos, recomposição de oito metros; de dois a quatro módulos, recomposição de 15 metros; de quatro a dez módulos, recomposição de 20 metros; e acima de 10 módulos, recomposição de 30 metros, sendo todas as situações descritas acima para córregos de até 10 metros de largura.

$\mathrm{Na}$ análise da tabela 1 pode-se observar que a FEPE é composta por 14 matrículas, das quais apenas três possuem área maior do que quatro módulos fiscais e com necessidade de averbação de Reserva Legal, que será realizada conforme dispõe o art. 12 da lei florestal 12.651/2012, através dos instrumentos previstos com ato declaratório mediante o Cadastro Ambiental Rural (CAR) e Programa de Regularização Ambiental (PRA), com regras gerais a serem determinadas pela União e diretrizes específicas pelos Estados. Nesse aspecto, só com a mudança na legislação, houve a desobrigação da aplicação de $20 \%$ para Reserva Legal sobre 373 hectares referentes à soma das oito matrículas, sendo que para regularização da FEPE seriam necessários aproximadamente 90 hectares de áreas destinadas a Reserva Legal.

Cabe destacar que essas matrículas apresentam apenas 56 hectares de vegetação nativa entre APP e fragmentos (Figura 1), com um déficit de aproximadamente 38\% da área destinada a Reserva Legal. Porém a nova legislação permite a inclusão das APP com vegetação nativa no cômputo das áreas de Reserva Legal (art. 15), assim como a compensação com áreas de vegetação nativa, desde que no mesmo bioma. Dessa forma, se considerarmos a soma das áreas das APP e dos fragmentos florestais, toda a FEPE passa a apresentar 98,55 hectares de vegetação nativa protegida. Outro fator a ser considerado para adequação ambiental nas propriedades acima de quatro módulos é a questão da desobrigação da complementação da Reserva Legal em propriedades que realizaram desmatamentos de acordo com que a legislação permitia (art. 68 da Lei 12.651/2012).

O memorial descritivo evidenciou que a propriedade possuía em 1972 apenas 30 hectares de vegetação nativa, ou seja, pelo direito adquirido, esta deveria ser a quantidade de área destinada como reserva atualmente. Assim, caso a FEPE seja considerada como uma única propriedade, continuará de acordo com a legislação atual, por ter área excedente de vegetação nativa.

Quanto às APP, pode-se identificar que houve redução de $30 \%$ da área protegida pela nova legislação, em função da diminuição da metragem de proteção. Em contrapartida, o fato de as áreas consolidadas como benfeitorias estarem de acordo com a legislação atual reduziu a área considerada irregular a apenas 0,5\% da área total da APP, enquanto na legislação anterior a irregularidade era de $20 \%$ da área total da APP.

Tabela 2. Situação florestal da propriedade.

Table 2. Forest situation of the property.

\begin{tabular}{lcc}
\hline Situação florestal da propriedade & Lei 4.771/1965 & Lei 12.654/2012 \\
\hline Número de matrículas considerado & 1 & 14 \\
Área de Preservação Permanente (APP) & 27,2 & 18,8 \\
APP com vegetação & 22 & 14,4 \\
APP degradada ou consolidada & 5,2 & 4,4 \\
Fragmentos florestais (excetuada APP) & 76,55 & 84,15 \\
Vegetação nativa total & 98,55 & 98,55 \\
Reserva Legal exigida & 164 & 98,55 \\
Déficit Reserva Legal & 65,45 & 0 \\
Área total protegida por lei & 191,2 & 98,55 \\
\hline
\end{tabular}

Diante do exposto, de acordo com a tabela 2, ao se comparar com a legislação florestal de 1965, a área de estudo está atualmente adequada, uma vez que os desmatamentos ocorreram de acordo com o permitido na época. Ressalte-se que foram restauradas as APP com o plantio de mais de 20.000 mudas nativas e conservaram-se os remanescentes de vegetação nativa existentes desde 1972. Tal fato contribui para garantir a qualidade e quantidade de água e biodiversidade de fauna e flora e evidencia a importância de uma legislação que proteja de maneira efetiva as florestas do país.

\section{CONCLUSÕES}

- De acordo com a Lei $n^{0} 4.771 / 65$, foi observada uma redução na área protegida por lei na propriedade de estudo, sendo 31\% em relação às APP e 40\% em relação à área para destinação da Reserva Legal. 
- Segundo a legislação atual (Lei $\left.n^{0} 12.651 / 2012\right)$, identificou-se que, em relação às APP, a FEPE necessita recompor 0,835 hectares para tornar-se totalmente regularizada. Anteriormente havia uma irregularidade de $20 \%$ da área ocupada, assim como para áreas de Reserva Legal, que apresentava um déficit de 54\%.

- Há necessidade de adoção de medidas de conservação das Áreas de Preservação Permanente e dos fragmentos florestais existentes na FEPE, como forma de garantir a sustentabilidade dessas áreas a médio e longo prazo.

\section{REFERÊNCIAS}

BARRELA, W. As relações entre as matas ciliares, os rios e os peixes. In: RODRIGUES, R. R.; LEITÃO FILHO, H. F. (Eds.). Matas ciliares: conservação e recuperação. São Paulo: EDUSP, 2000. p. 187 - 207.

COGO, N. P.; LEVIEN, R.; SCHUARZ, R. A. Perdas de solo e água por erosão hídrica influenciadas por métodos de preparo, classes de declive e níveis de fertilidade do solo. Revista Brasileira de Solo, Viçosa, v. 27, n. 4, p. 743 - 753, 2003.

MACHADO, P. A. L. Direito ambiental brasileiro. 7. ed. São Paulo: Malheiros, 1999. 894 p.

MILARÉ, E.; MACHADO, P. A. L. Novo Código Florestal. 1. ed. São Paulo: RT, 2012. 510 p.

LIMA, W. P.; ZAKIA, M. J. B. Hidrologia de matas ciliares. In: RODRIGUES, R. R.; LEITÃO FILHO, H. F. Matas ciliares: conservação e recuperação. São Paulo: EDUSP/ Fapesp, 2000. cap. 3, p. 33 - 44.

METZGER, J. P. Tree functional group richness and spatial structure in a tropical fragmented landscape (SE Brazil). Ecological Applications, v. 10, p. 1147 - 1161, 2000.

PINTO, M. M. Levantamento fitossociológico de mata residual situada no Campus de Jaboticabal da UNESP. 114 f. Dissertação (Mestrado em Agronomia) - Universidade Estadual Paulista. Jaboticabal, 1989.

RIBEIRO, C. A. A. S.; SOARES, V. P.; OLIVEIRA, A. M. S.; GLERIANI, J. M. O desafio da delimitação de áreas de preservação permanente. Revista Árvore, Viçosa. v. 29, n. 2, 2005.

RODRIGUES, R. R.; GANDOLFI, S.; NAVE, A. G.; BARRETO, T. E.; VIDAL, C. Y.; BRANCALION, P. H. S. Large-scale ecological restoration of high-diversity tropical forests in SE Brazil. Forest Ecology and Management, v. 261, n. 10, p. 1605 - 1613, 2011.

TABANEZ, A. A.; VIANA, V. M. Patch structure whithin brazilian Atlantic Forest fragments and implications for conservation. Biotropica, v. 32, n. 4b, p. 925 - 933, 2000.

VALERI, S. V. Reflorestamento em área de preservação permanente e enriquecimento de remanescentes florestais da FCAV/UNESP. Jaboticabal: Unesp, 2004. 37 p. 
